\title{
ASSESSING THE VARIABILITY OF INFLOWS AT ASWAN HIGH DAM DUE TO OUTFLOW CHANGES FROM VICTORIA LAKE RESULTING FROM CLIMATE CHANGE
}

\author{
Mohamed Nour El Dien, Aly El. Bahrawy, Ayman Nasar, Sherien Zahran
}

\begin{abstract}
In this research the Nile Decision Support System (NILE-DST) was tooled to assess the variability of the inflows at Aswan High Dam (AHD) due to the outflow changes from Victoria Lake resulting from climate changes and the increase in water demands. Different scenarios were established where the outflow from Victoria Lake was decreased by $3,10,18,25,37,55,75$ and $100 \%$. The scenarios considered a time span of 63 years (1913-1976) in which a natural flow period (1913-1976), a dry period (1920-1960) and a wet period (1961-1976) were distinguished. The model was run and results of inflows at the different river nodes (i.e. Victoria Lake, Packwash, Mogalla, Sudd Exit, Malakal, Gabl El-Aulia, Dongola and AFD) and the properties of the reservoirs (i.e. storage capacity, water level and evaporation)] were obtained. These results were analyzed and plotted. From these plots the impact of the variability in the outflow from Victoria on the AHD was assessed. On the other hand, an adaptive solution (constructing a diversion canal "Jonglie Canal" to by-pass the swamps in order to decrease the evaporation losses) was proposed in order to compensate for the inflow reduction at AHD. As a conclusion from this research, it was found that the AHD will be considerably affected by the variability of the outflows from Victoria Lake. It was also found that Jonglie Canal would serve as a compensator.

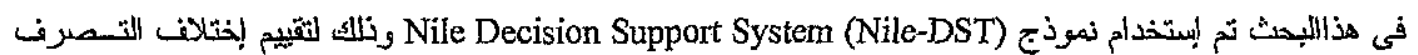

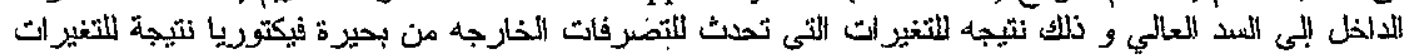

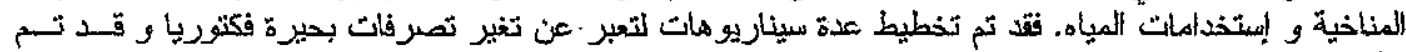

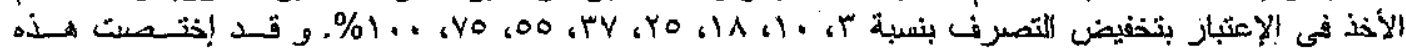

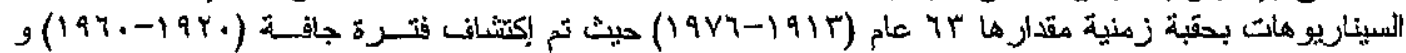

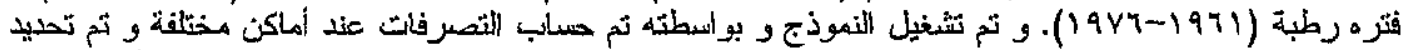

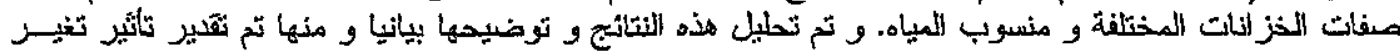

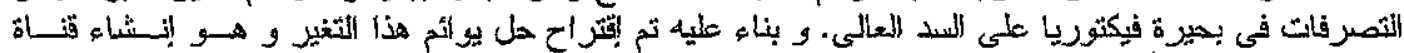

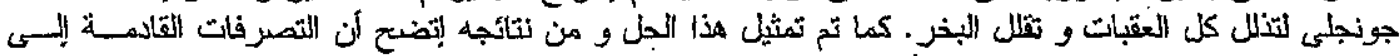

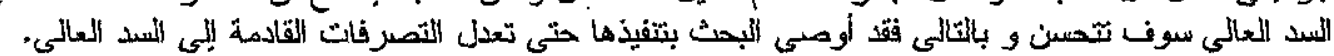

Keywords: Nile Decision Support System, Aswan High Dam, Victoria Lake, Jonglie Canal.

\section{INTRODUCTION}

The Nile River Basin is a major basin in the world where its inhabitants are especially sensitive to climate change. Along its $3,000 \mathrm{~km}$ course, the Nile losses a huge amount of water by evaporation. This makes water supply extremely sensitive to temperature and precipitation variations. Climate change is thus likely to impose additional pressures on water availability, water accessibility and water demand in Africa. The population at risk, due to water stress, in Africa is expected to be between 75250 million and 350-600 million by years 2020 and 2050, respectively, IPCC (2007).

This study was thus initiated with the objective of assessing the variability of the inflows at Aswan High Dam (AHD) due to the outflow changes from Victoria Lake resulting from climate changes and the increase in water demands. In this paper, the following are displayed:

- an overview to the Nile River Basin together with Victoria Lake

- the tooled NULE-DST "Nile Decision Support System" so as its theory and structure

- the established scenarios to Victoria Lake outflows and their assumptions

- the analysis, results and the adaptive solution (Jonglie Canal)

- conclusions and recommendations

\section{NILE RTVER BASIN AND VICTORIA LAKE}

Regarding the Nile River Basin, Figure (1), its annual runoff potential is estimated to be approximately 85 billion cubic meters (BCM). The Nile River Basin has low specific discharge (total 
runoff per drainage area) as compared to other major river basins and exhibits great difference in water availability among the sub-basins. The per capita availability of water in the Nile Basin countries will decrease due to population growth. Thus, the per capita availability of water for lower riparian countries is highly dependent upon mutual cooperation with upstream countries. Moreover, the trans-boundary nature of the river further aggravates the problem. As for the Nile River, it is a home and source of livelihood to approximately 160 million people. It is the longest river in the world with a total length of $6700 \mathrm{~km}$. It traverses an extremely wide band of latitudes, from $4^{\circ}$ south to $32^{\circ}$ north. The total area draining into the Nile River system is about 3 million $\mathrm{km}^{2}$ and extends over 10 African countries. Regarding Victoria Lake, Figure (2), it is located in the middle of the three Eastern African countries. Most of its northern half is in Uganda, southern half in Tanzania and a relatively small northeastern portion gulfing into Kenya. The lake shores are shared by three countries (i.e. Tanzania, Uganda and Kenya). The lake is located within $0.2^{\circ} \mathrm{N}-3.0^{\circ} \mathrm{S}$ and $31.5^{\circ} \mathrm{E}-34.5^{\circ} \mathrm{E}$. It is $400 \mathrm{~km}$ long and $280 \mathrm{~km}$ wide. Its extensive water surface is situated at an altitude of $1134 \mathrm{~m}$ AMSL. The lake's drainage basin covers an area of about $195,000 \mathrm{~km}^{2}$ that extends to parts of Rwanda and Burundi to the west of the lake. Compared to other lakes, Victoria Lake is quite shallow; with mean (maximum) depth of $40 \mathrm{~m}(84 \mathrm{~m})$ and a coastline of about $3440 \mathrm{~km}$. Victoria Lake Basin climate is characterized by periodic episodes of wet/dry conditions. Some recent events include the $1961 / 62,1997 / 98$ and $1997 / 98$ floods that left behind a huge trail of damage to property and infrastructure. On the other hand, the lake water temperatures usually follow the magnitude of solar radiation input but with some lag. Over the lake surface, the mean monthly solar radiation is estimated to be $240-270$ $\mathrm{W} / \mathrm{m}^{2}$ and the surface water temperatures ranges between $24^{\circ} \mathrm{C}$ and $28^{\circ} \mathrm{C}$. The temperature so as human activities and amount of precipitation affect the lake level.

\section{NILE-DST MODEL (THEORY AND STRUCTURE)}

The Nile Decision Support Tool was developed as part of the Nile Basin Water Resources Project under the sponsorship of the Food and Agriculture Organization of the United Nations (FAO). The NileDST was developed in Georgia Institute of Technology. It includes six main components namely database, river simulation and management, agricultural planning, hydrologic modeling, remote sensing and water quality. Regarding the theory of the model, it is based on a set of equations which describe the response of the various system elements (reservoir and routing model reaches) to various inflow and release scenarios. The dynamics of the reservoirs are modeled by water balance equations, while that of the routing reaches by the routing equation, Yao and Georgakakos, (2003). As for the Nile RSM, its function is to process the data and quantify the response of the basins to water use, and development/management scenarios. The Nile RSM includes models that fall under the categories of river-reservoir simulation, system optimization and scenario assessment. Regarding the structure of the NileDST-RBM, it includes 14 existing and planned reservoirs (Victoria, Kyoga, Albert, Gebel Ailia, Tana, Karadobi, Mabil, Mendaia, Border, Roserires, Sennar, Girba, Merwe, AHD), 20 existing and planned hydro power plants (Owen Falls, Bujagali, Kalagala, Karuma, Ayogo North, Ayago South, Murchison, Tana, TanaBeles, Karadobi, Mabil, Mendaia, Border, Roseires, Sennar, Girba, Merowe, AHD, OAD, and Toshka), 13 inflow nodes, 16 river nodes (Victoria Lake, Packwash, Mongalla, Sudd Exit, Malakal, Gabal El-Aulia, Dongola and AHD), and 15 demand nodes, Figure (3).

\section{PROPOSED SCENARIOS AND ASSUMPTIONS}

The average annual outflow from Victoria Lake during the period 1913-1976 was 27 BCM. Eight (8) scenarios were proposed to represent the outflow from Victoria Lake. The proposed scenarios were to decrease the outflow from Victoria Lake by $3,10,18,25,37,55,74,100 \%$ (i.e. $1,3,5,7,10,15,20,27$ BCM which represent $26,24,22,20,17,12,7,0$ BCM, respectively). It is to be noted that increasing the outflow was considered but is not displayed in this paper. The proposed scenarios were based upon an assumption. This assumption is "water outflow from Victoria Lake might decrease due to":

- producing food by irrigation water not by rain which might cause the consumptive potentially to increase by 5-10 BCM per year over the next 40 to 50 years

- climate change and withdrawal increase to meet the human activities

On the other hand, a reference scenario was established for comparison purposes. The rules used for this scenario were as follows:

- Victoria, Kyoga, and Albert Lakes follow the natural outflow policy.

- Roseries, Sennar, and Girba follow the customized operating rules used in practice.

- The AHD releases according to the downstream demand target levels

- The Gebel El Aulia reservoir operates according to its target elevation rule.

The above scenarios were simulated under three cases. These are:

- Natural flow during the period (1913-1976) 
Nour El Dien, M., El. Bahrawy, A., Nasar, A., Zahran, S., "Asssessing the Variability of Inflows at Aswan ... "

- Wet period (1920-1960)

- Dry period (1961-1976)

\section{ANALYSIS, RESULTS AND ADAPTIVE SOLUTION}

From the simulated scenarios results (i.e. water levels, storage, net evaporation of the reservoirs so as the inflows to the nodes) were obtained, analyzed and presented. It is to be noted that only a sample of the results at AHD is given here. Figure (4), (5) and (6) show the average annual inflows for all the modeled scenarios at $\mathrm{AHD}$, during the natural flow period (with a maximum of $100 \quad B C M$ ), dry and wet periods, respectively. On the other hand, Figures $(7 \mathrm{a}, \mathrm{b}, \mathrm{c})$ show the quantity, change and \% change in the inflow at AHD as a result of decreasing the outflow from Victoria Lake during the natural flow period, respectively. As for Figures $(8 \mathrm{a}, \mathrm{b}, \mathrm{c})$ and $(9 a, b, c)$ they show the same but for the dry and the wet periods, respectively. The obtained quantity, change and percentage change of inflow at AHD were subjected to a regression analysis from which the equations representing the impact trends were obtained and are given on these figures and Table (1). On all the above figures, the reference scenario results are given for comparison purposes.

Based on the above figures, clear was that the AHD would be affected by $0.25-4.5,0.25-4$ and $0.3-5.5 \%$ due to the outflow decrease from Victoria Lake (by $3-100 \%$ ) during the natural flow period, dry and wet periods, respectively . Therefore, an adaptive solution was proposed. This solution was to implement a diversion canal that could avoid any obstruction (i.e. swamps) in order to decrease the evaporation losses. This diversion is Jonglie Canal (360km long). It originates from Bahr El-Gabal and flows till it meets the White Nile at the upstream junction to Sobat. The canal will be implemented in 2 phases (phase 1: carrying $20 \mathrm{Mm}^{3} / \mathrm{d}$ and phase 2: carrying $40 \mathrm{Mm}^{3} / \mathrm{d}$ ). This canal was simulated by the model under the different scenarios. The results were obtained, analyzed and presented on Figures (10), (11), (12) and (13). They show the:

- inflow at the AHD after operating Jonglie Canal phase 1 and 2 (the inflow increased from $a$ maximum of 100BCM, Figure (4), to be > $100 B C M$ after the operation of Jonglie Canal)

- water level at $\mathrm{AHD}$ that will range between 180 and $170 \mathrm{~m}$, after operating Jonglie Canal Phase 1 and 2

- AHD storage that will range between 142 and 70 BCM, after operating Jonglie Canal Phase 1 and 2

- net evaporation at AHD that will range between 16 and $9 \mathrm{BCM}$, after operating Jonglie Canal Phase 1 and 2

\section{CONCLUSIONS AND RECOMMENDATIONS}

\section{From the above figures, it was concluded that:}

- The inflow at AHD would be reduced by 0.25 $4.5,0.25-4$ and $0.3-5.5 \%$ due to the outflow decrease from Victoria Lake (by $3-100 \%$ ) during the natural flow period, dry and wet periods, respectively. This means it will be mainly affected during the wet period, relatively less affected during the natural flow period and the least effect occurs during the dry period.

- The established graphs [figures (7,8 and 9)] could foresee the quantity, change and \% change in the inflow at AHD due to the decrease in the outflow from Victoria Lake.

- The derived equations [Table (1)] could predict the quantity, change and \% change in the inflow at AHD due to the decrease in the outflow from Victoria Lake.

- The derived equations would support decision makers to predict and manage the water inflows at the AHD during wet (floods) and dry seasons (droughts).Using such equations might reduce the hazards during floods as precautions will be previously undertaken.

- Jonglie canal proved to be a reasonable adaptive solution that might compensate the reduction of the inflow at $\mathrm{AHD}$.

- After operating Jonglie Canal Phase 1 and 2, the following will occur:

- The inflow at AHD will increase from a maximum of $100 \mathrm{BCM}$ (before operating the canal) to be $>100 \mathrm{BCM}$.

- The water level at AHD will be between 180 and $170 \mathrm{~m}$.

- AHD storage will be between 142 and 70 $\mathrm{BCM}$.

- The net evaporation at AHD will be between 16 and 9 BCM.

\section{It is thus further recommended to:}

- execute more researches to predict climate variability at local and regional scale

- undertake more research in the field of decision support system modeling for the entire watershed areas in Nile basin

- develop an integrated plan for adaptation and mitigation of the impact of climate changes

- develop a socio-economic and an environmental modules linked with the DST-NILE basin to study the assessment of the impacts on sustainable development

\section{REFERENCES}

[1] Georgakakos, A.P., and H. Yao, (2003). The Nile Decision Support Tool (Nile DST): River and Reservoir Simulation and Management, prepared 
Nour El Dien, M., El. Bahrawy, A., Nasar, A., Zahran, S., "Assessing the Variability of Inflows at Aswan ... "

for the Food and Agriculture Organization of the United Nations, Technical Report, Georgia Water Resources Institute and Georgia Tech.

[2] $I P C C$, 2007. Working Group II Fourth Assessment Report: Impacts, Adaptation and Vulnerability. Available online at www.ipccwg2.org

[3] Johns, T. and Co-authors, 2005. HadGEM1 Model description and analysis of preliminary experiments for the IPCC Fourth Assessment Report. Hadley Centre Technical Note 55, Met Office, UK, $74 \mathrm{pp}$.

[4] Mohamed, Y.A., van den Hurk, J.J.M., Savenije, H.H.G. and Bastiaanssen, W.G.M., 2005. Hydroclimatology of the Nile: results from a regional climate model. Hydrol. Earth Syst. Sci. Discuss., 2, 319-364.

[5] New, M., Hulme, M. and Jones, P., 2000. Representing twentieth-century space-time climate variability. Part II: Development of 190196 monthly grids of terrestrial surface climate. J.Climate, 13(13), 2217-2238.

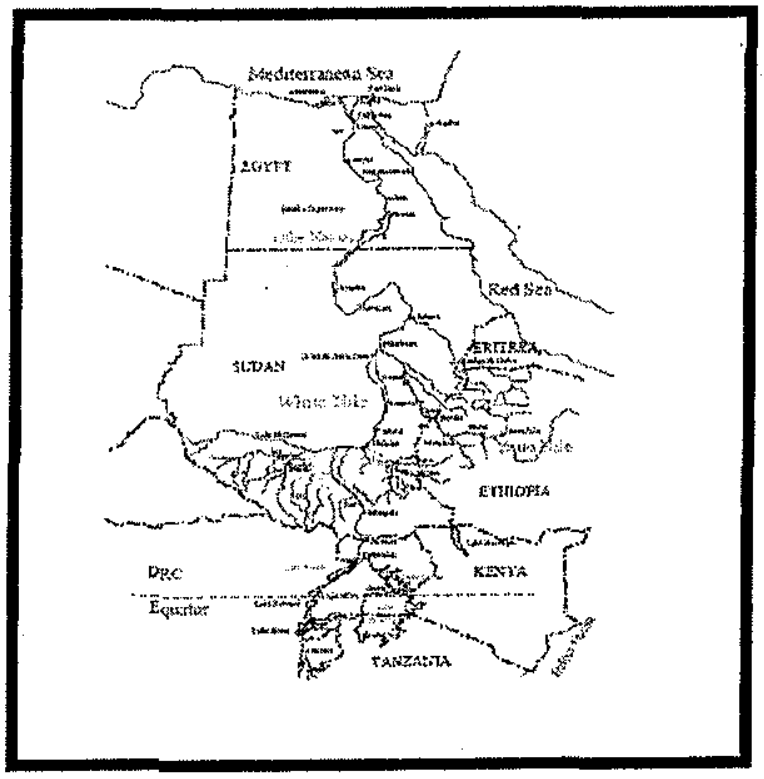

Figure (1): A map of the Nile Basin

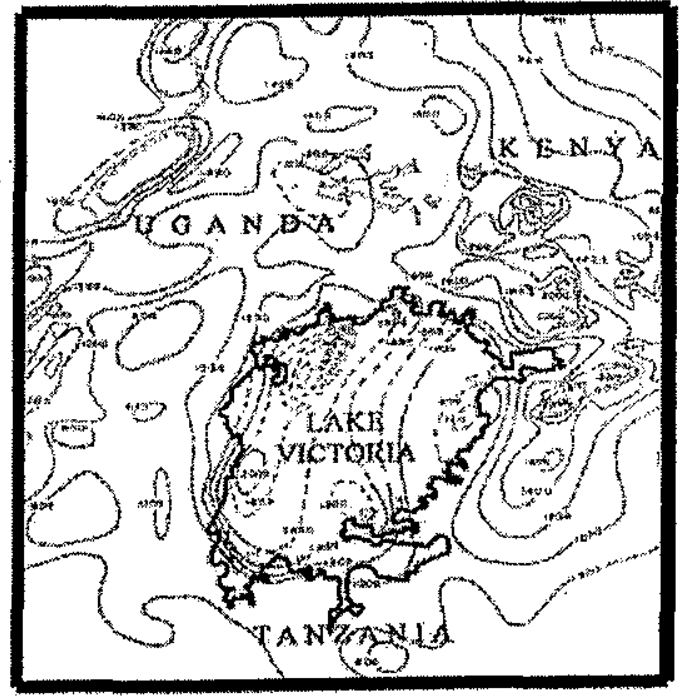

Figure (2) Victoria Lake Basin

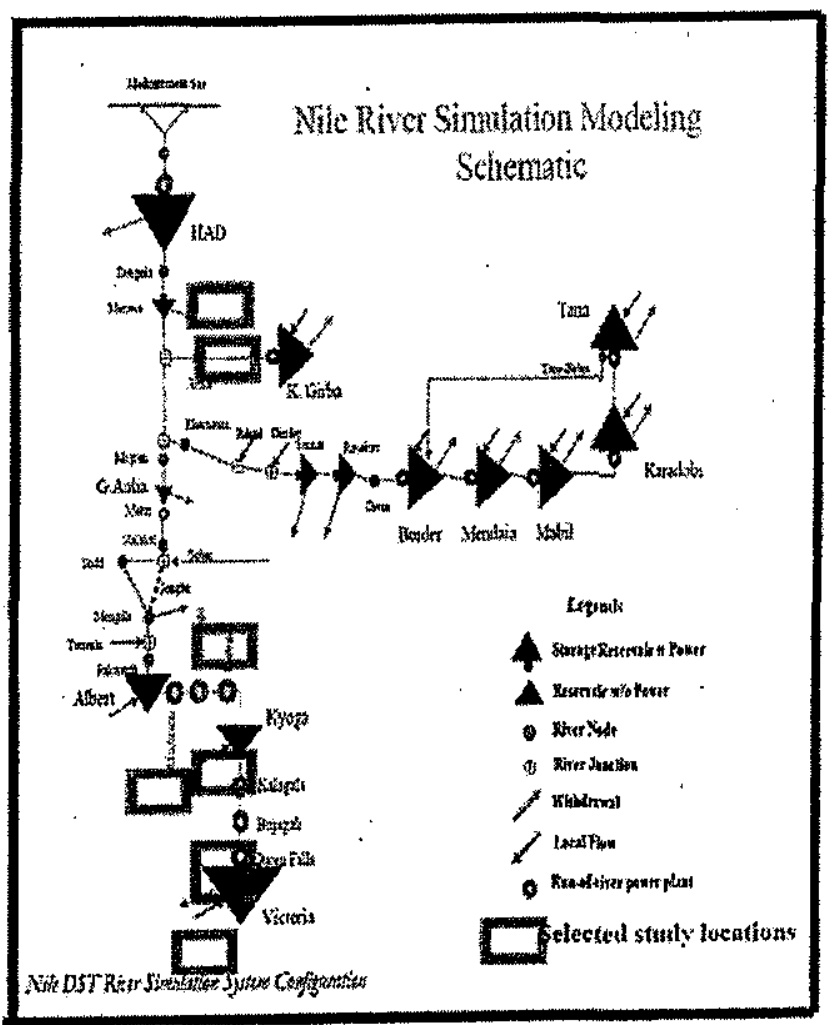

Figure (3) Scheme of Nile-DST 
Nour El Dien, M., El. Bahrawy, A., Nasar, A., Zahran, S., "Assessing the Variability of Inflows at Aswan ... "

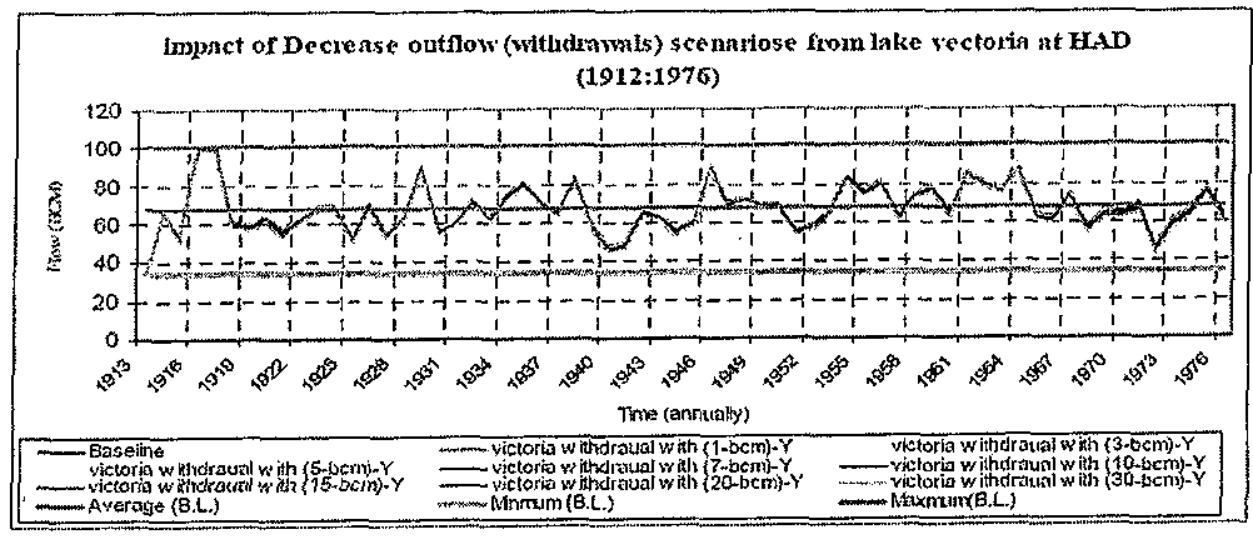

Figure (4) Average annual hydrograph for the different scenarios at $\mathrm{HAD}$ during the period of natural flow 1913-1976

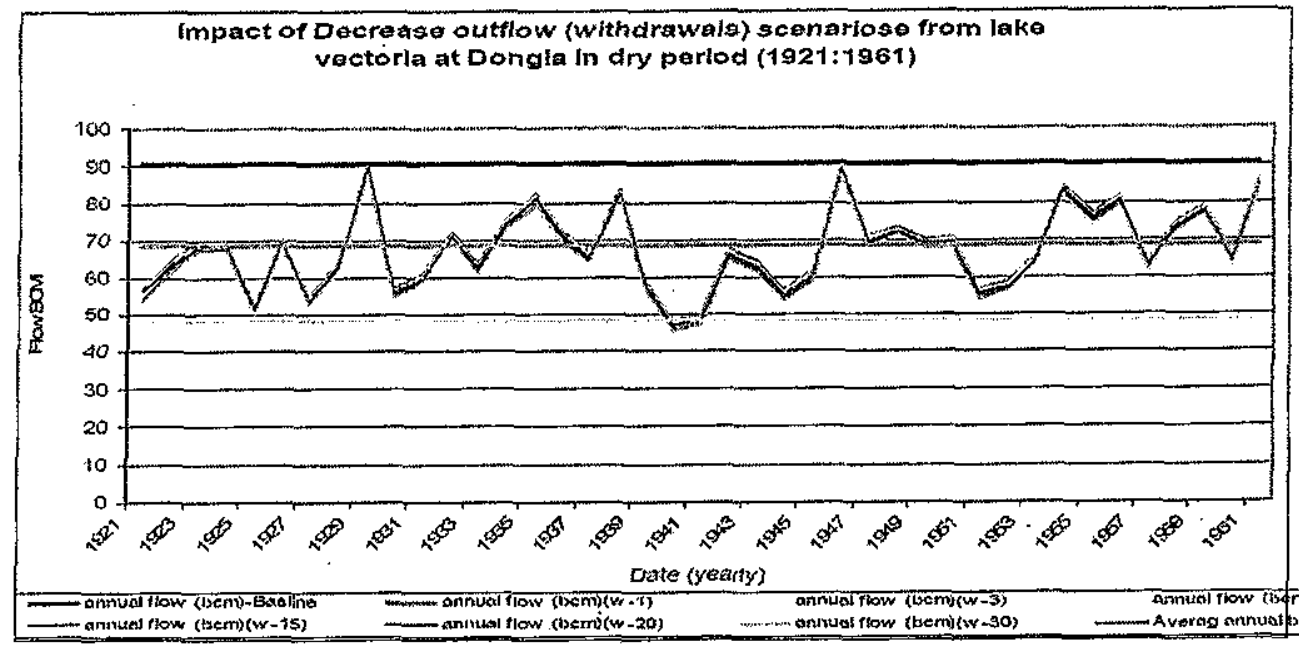

Figure (5) Average annual hydrograph for the different scenarios at HAD during the dry period $1920-1960$

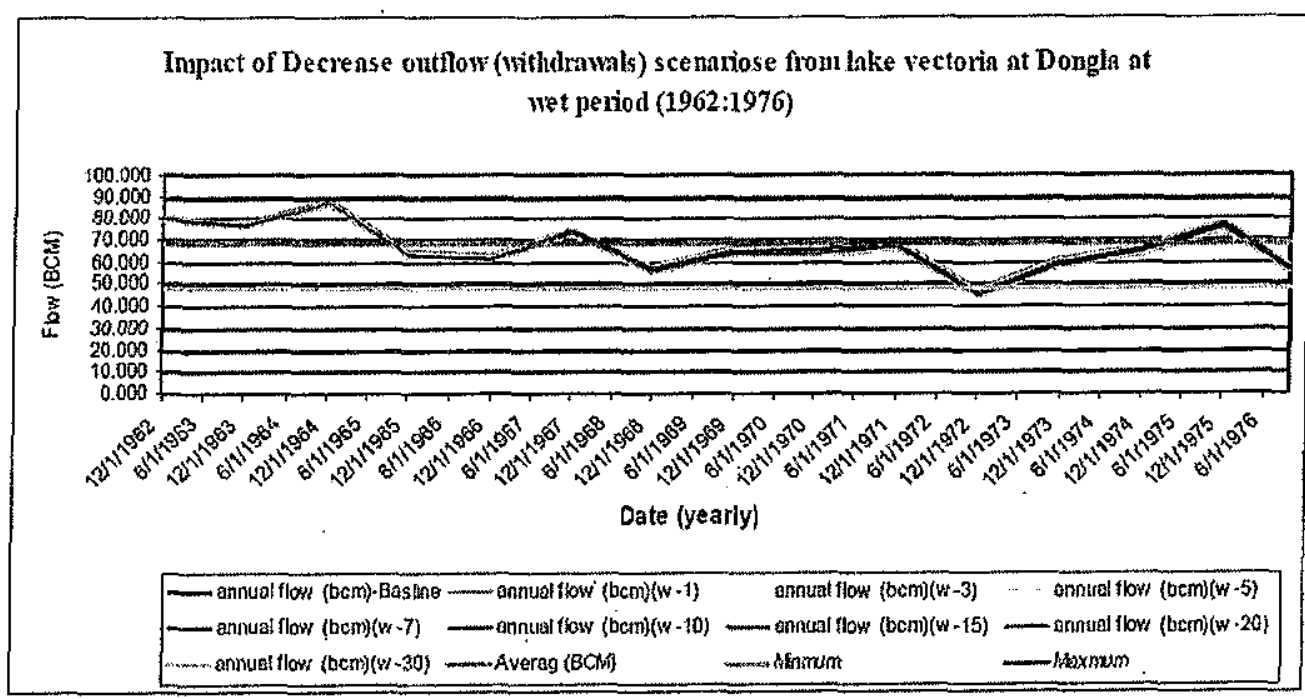

Figure (6) Average annual hydrograph for the different scenarios at $\mathrm{HAD}$ during the wet period 1961-1976 


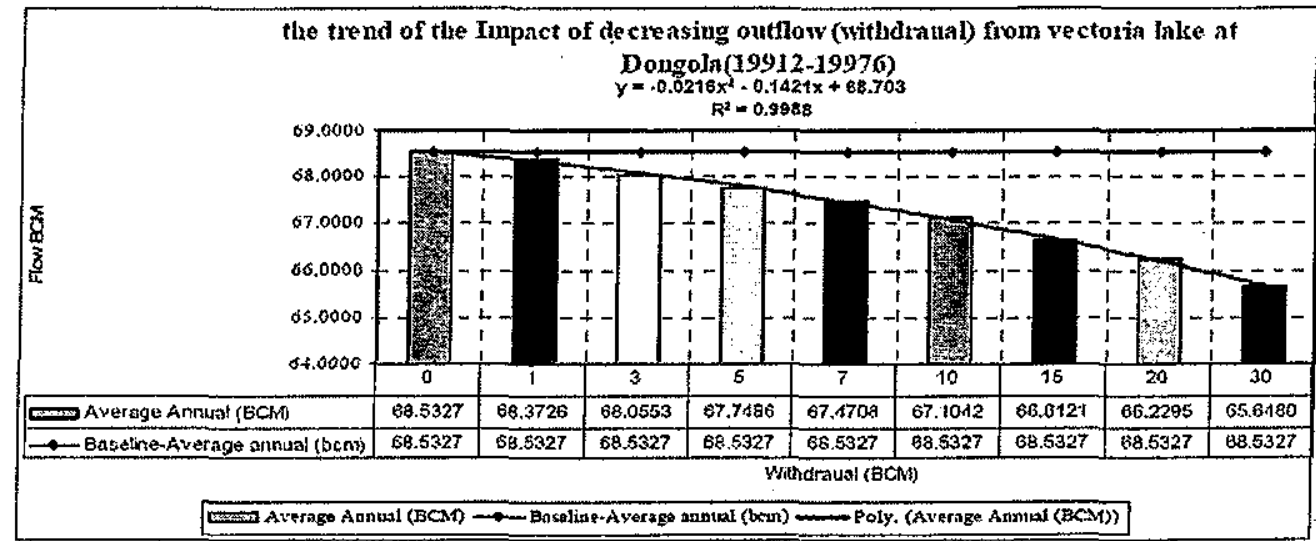

Figure (7a) The trend of the inflow at AHD for the different scenarios during the period of natural flow 1913-1976

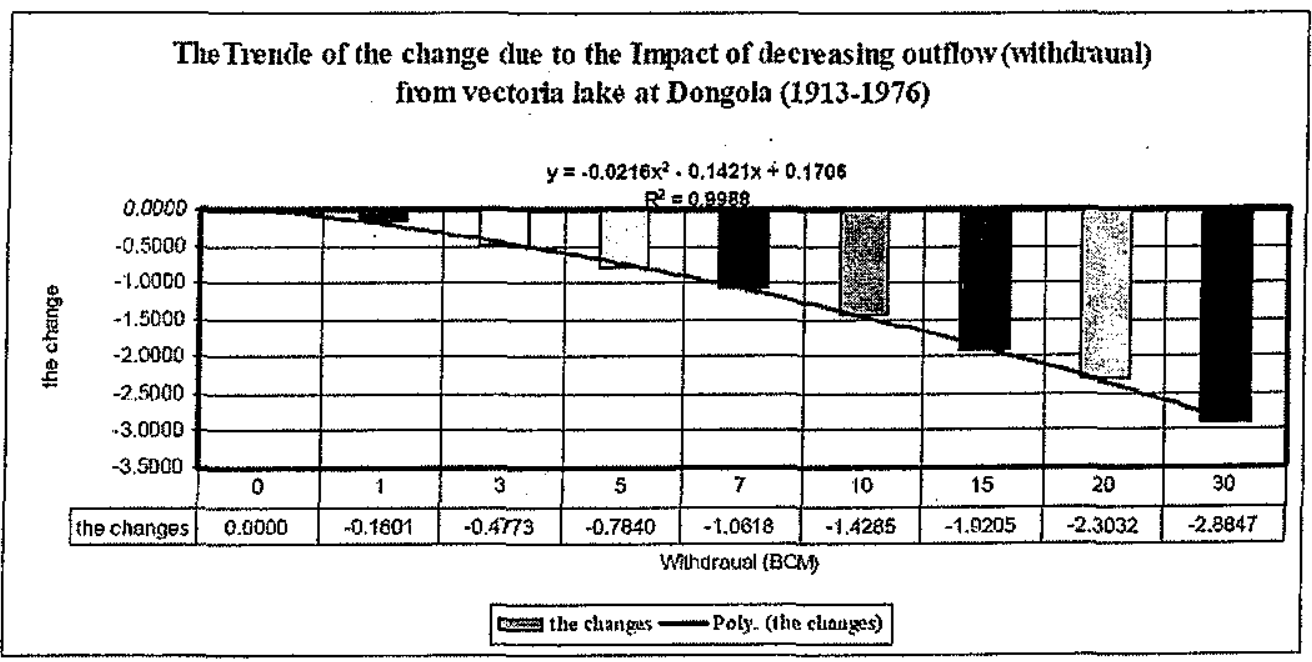

Figure (7b) The trend of the change in the inflow at AHD for the different scenarios during the period of natural flow 1913-1976

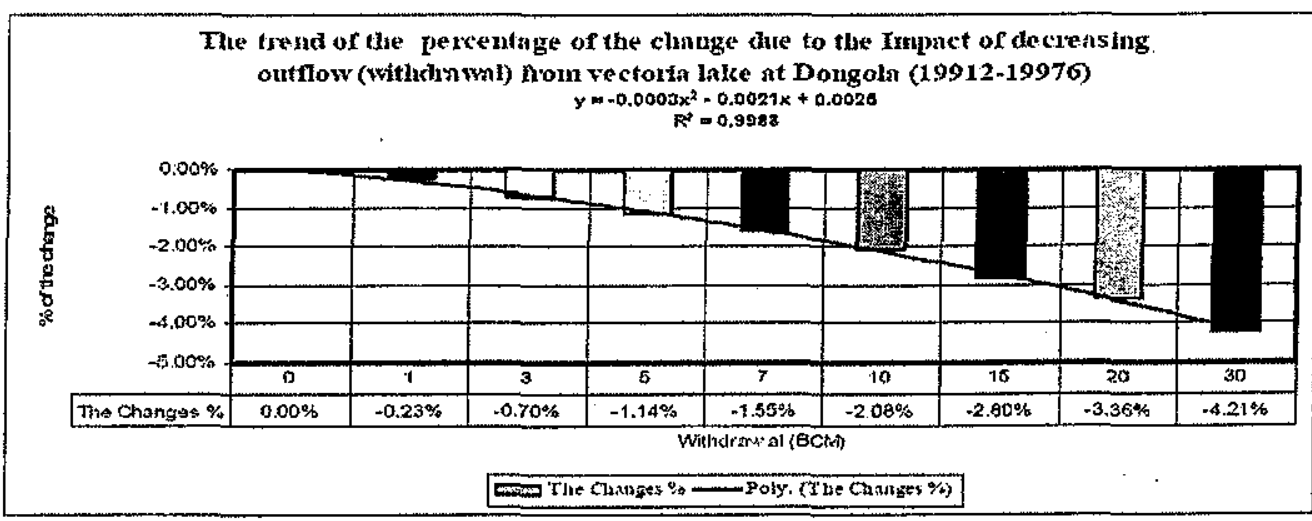

Figure (7c) The trend of $\%$ change in the inflow at AHD for the different scenarios during the period of natural. flow 1913-1976 
Nour El Dien, M., El. Bahrawy, A., Nasar, A., Zahran, S., "Assessing the Variability of Inflows at Aswan ... "

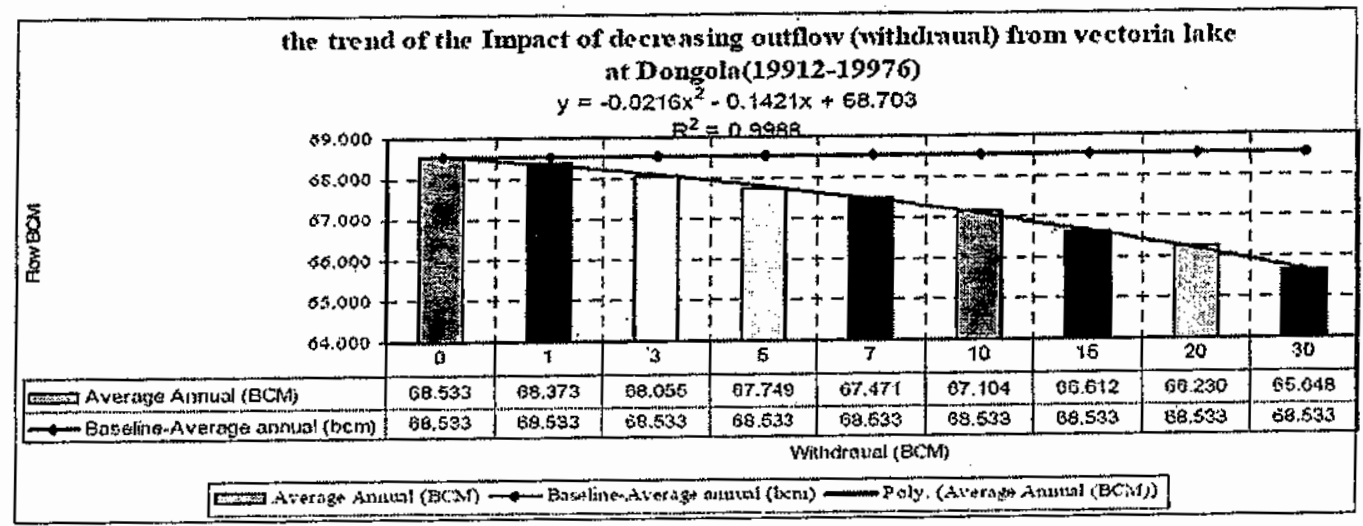

Figure (8a) The trend of the inflow at AHD for the different scenarios during the dry period 1920-1960

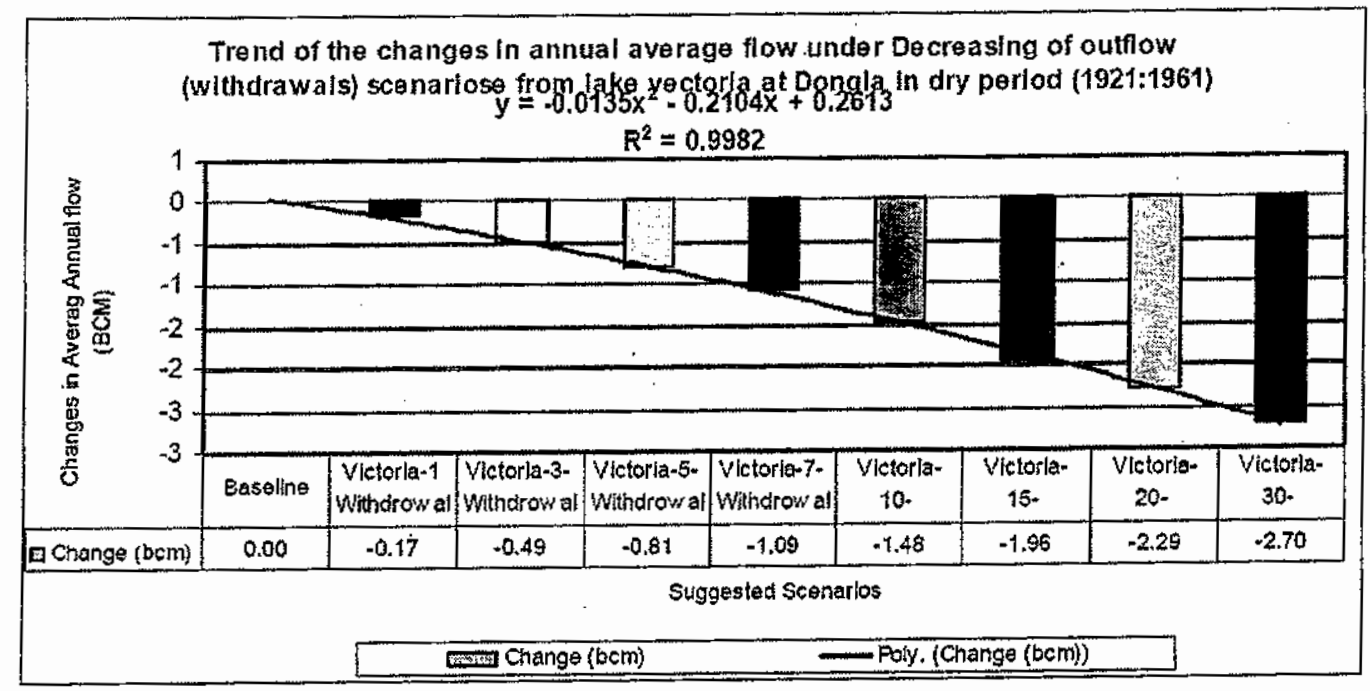

Figure (8b) The trend of the change in the inflow at AHD for the different scenarios during the dry period 1920-1960

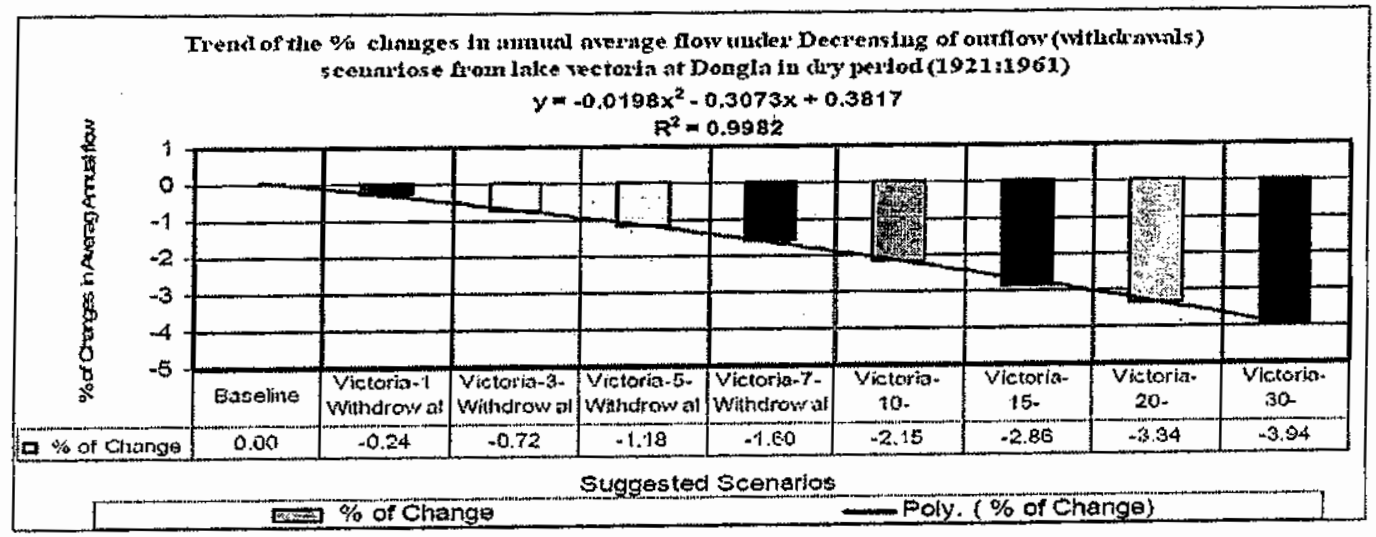

Figure (8c) The trend of $\%$ change in the inflow at AHD for the different scenarios during the dry period 1920-1960 
Nour El Dien, M., El. Bahrawy, A., Nasar, A., Zahran, S., "Assessing the Variability of Inflows at Aswan ... "

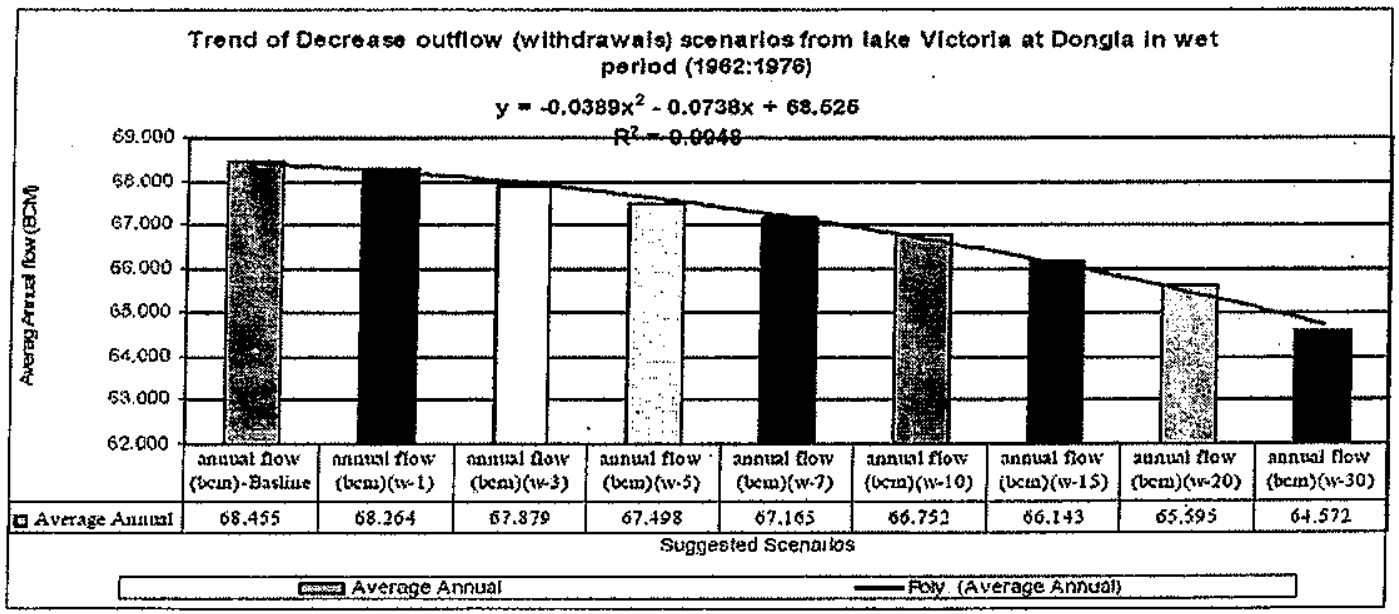

Figure (9a) The trend of the inflow at AHD for the different scenarios during the wet period 1960-1976

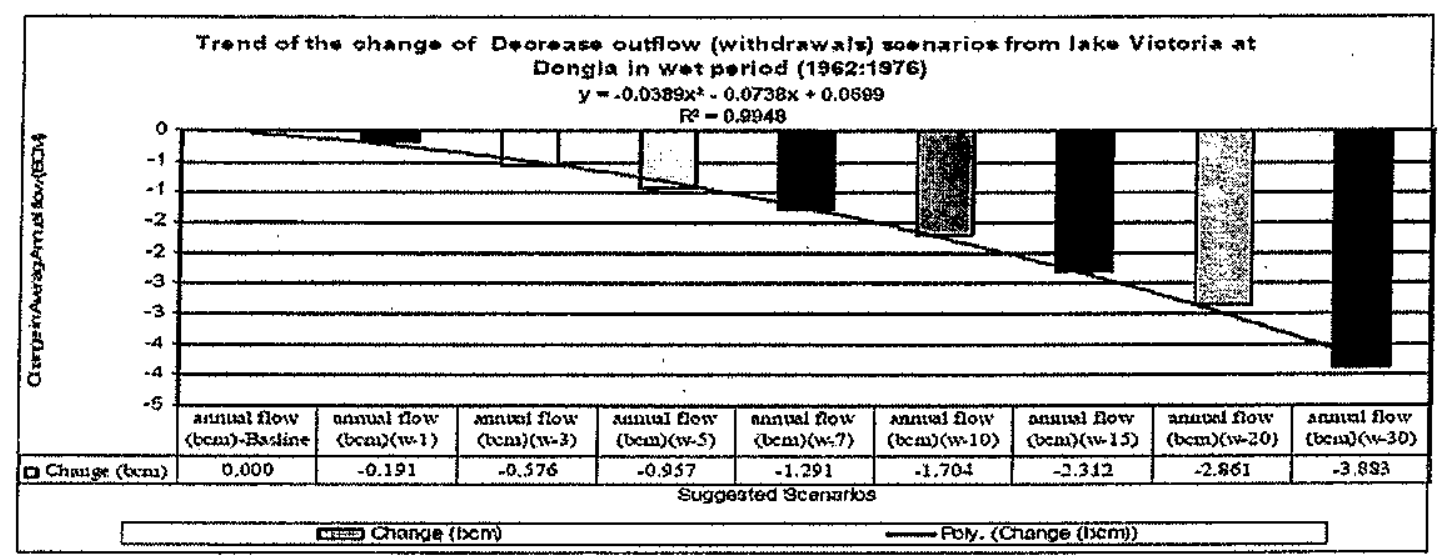

Figure (9b) The trend of the change in the inflow at AHD for the different scenarios during the wet period 1960-1976

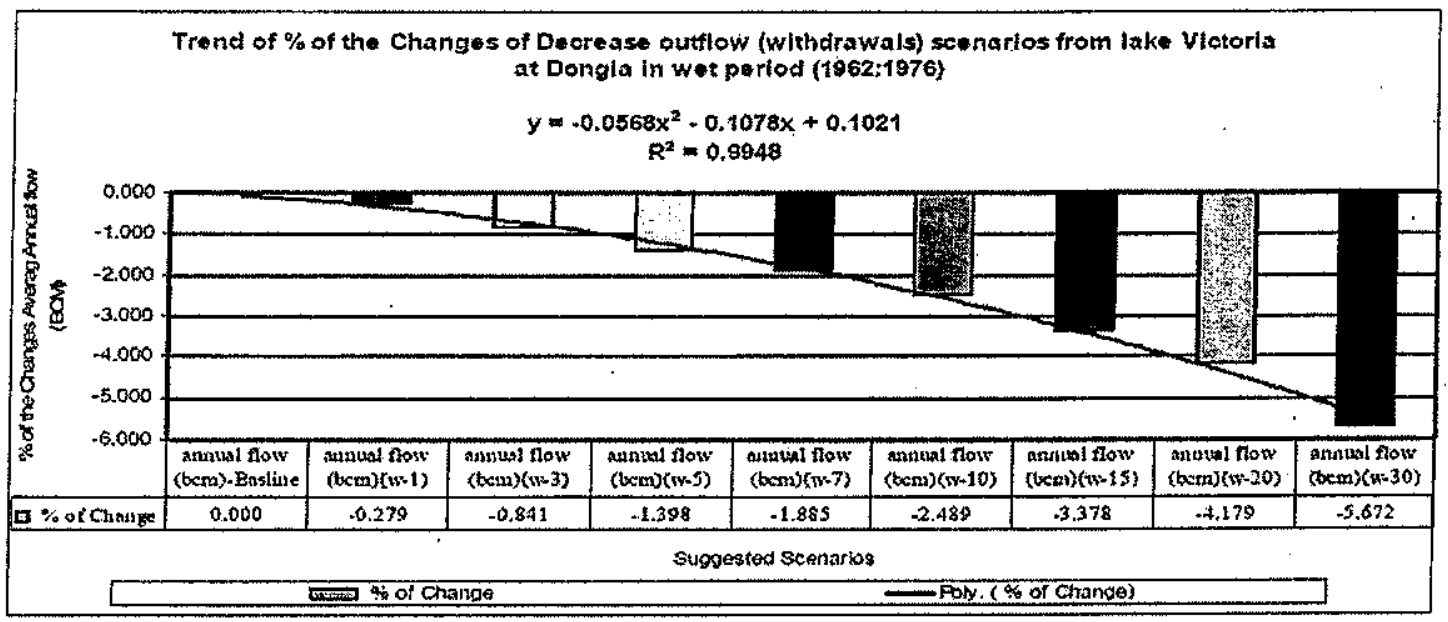

Figure (9c) The trend of $\%$ change in the inflow at AHD for the different scenarios during the wet period 1960-1976 
Nour El Dien, M., El. Bahrawy, A., Nasar, A., Zahran, S., "Assessing the Variability of Inflows at Aswan ..."

Table(1) The equations defining the trends of the quantity, change and \% change of the inflow at AHD due to the decrease in the outflow from Victoria Lake During the natural flow period, dry and wet periods.

\begin{tabular}{|c|c|c|c|}
\hline Trend: & Equation & $\mathbf{R}^{2}$ & Type \\
\hline \multirow{4}{*}{ Flow (BCM) } & Natumal Case & & \\
\hline & $Y 1=-0.0216 x-0.1421 x+68.703$ & $R^{2}=0.9988$ & Quadratic \\
\hline & $Y 1=-0.0135 x-0.2104 x+68.717$ & $R^{2}=0.9982$ & Quadratic \\
\hline & $Y 1=-0.0389 x-0.0738 x+68.525$ & $R^{2}=0.9948$ & Quadratic \\
\hline \multicolumn{4}{|c|}{ Dry Period } \\
\hline \multirow{3}{*}{ Changes (BCM) } & $Y 2=-0.0216 x-0.1421 x+0.1706$ & $\mathrm{R}^{2}=0.9988$ & Quadratic \\
\hline & $y 2=-0.0135 x-0.2104 x+0.2613$ & $R^{2}=0.9982$ & Quadratic \\
\hline & $Y 2=-0.0389 x-0.0738 x+68.525$ & $R^{2}=0,9948$ & Quadratic \\
\hline \multicolumn{4}{|c|}{ Wet Period } \\
\hline \multirow{3}{*}{$\%$ of Change } & $Y 3=-0.0003 x-0.0021 x+0.0025$ & $R^{2}=0.9988$ & Quadratic \\
\hline & $Y 3=-0.0198 x-0.3073 x+0.3817$ & $R^{2}=0.9982$ & Quadratic \\
\hline & $Y 3=-0.0568 x-0.1078 x+0.1021$ & $R^{2}=0.9948$ & Quadratic \\
\hline
\end{tabular}

Where

Y1: The inflow at AHD

Y2: the changes in the inflow at AHD

Y3: the percentage change in the inflow at AHD

$X$ : the decrease in the outflow from Victoria Lake

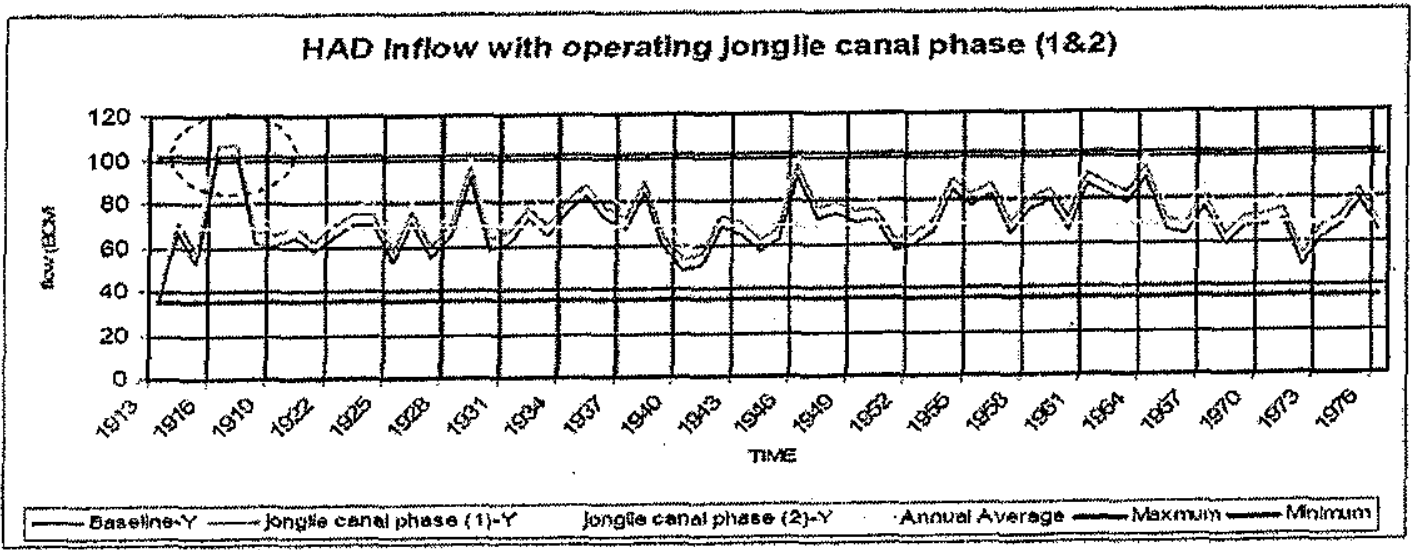

Figure (10) inflow at AHD after operating Jonglie Canal phase 1 and 2

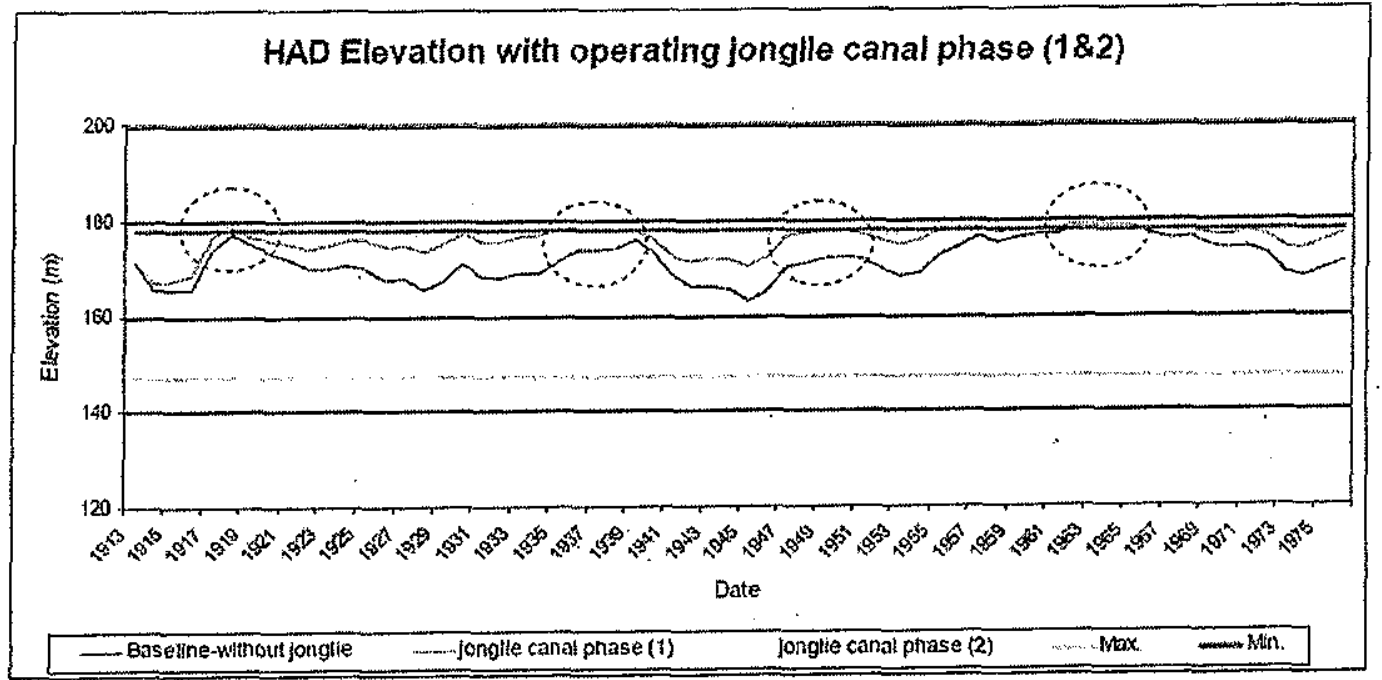

Figure (11) the water level at $\mathrm{AHD}$ after operating Jonglie Canal Phase 1 and 2 
Nour El Dien, M., El. Bahrawy, A., Nasar, A., Zahran, S., "Assessing the Variability of Inflows at Aswan ... "

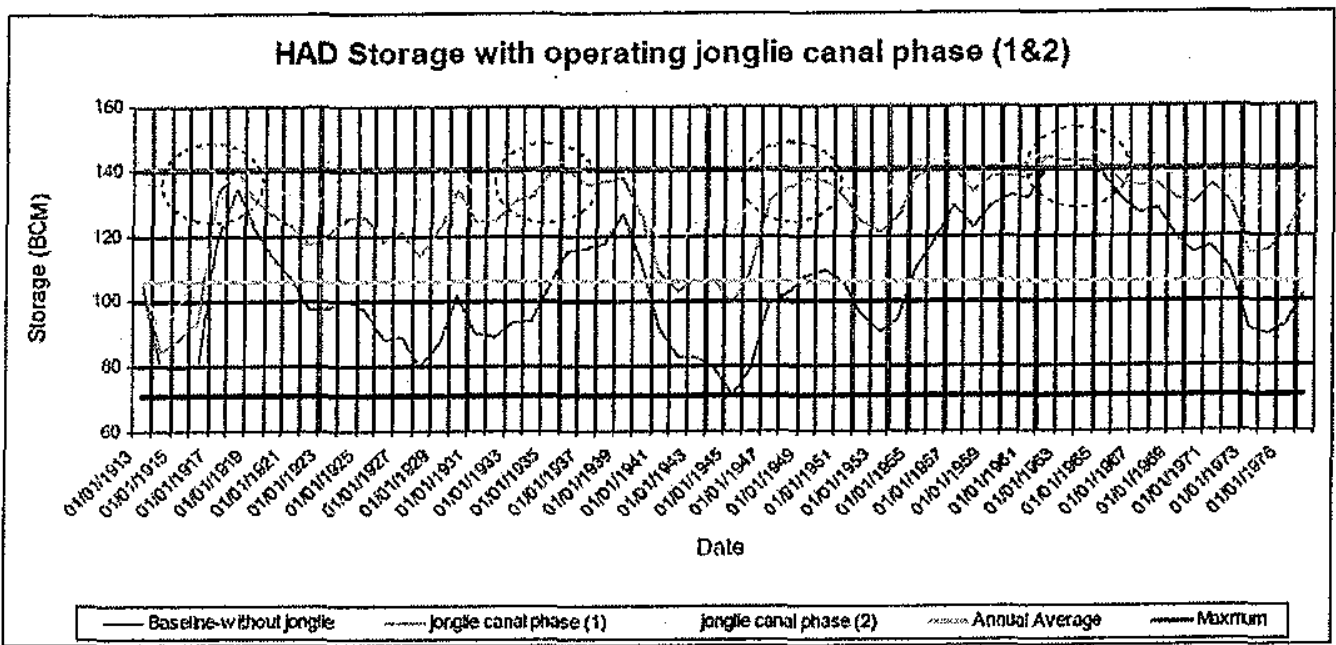

Figure (12) AHD storage after operating Jonglie Canal Phase 1 and 2

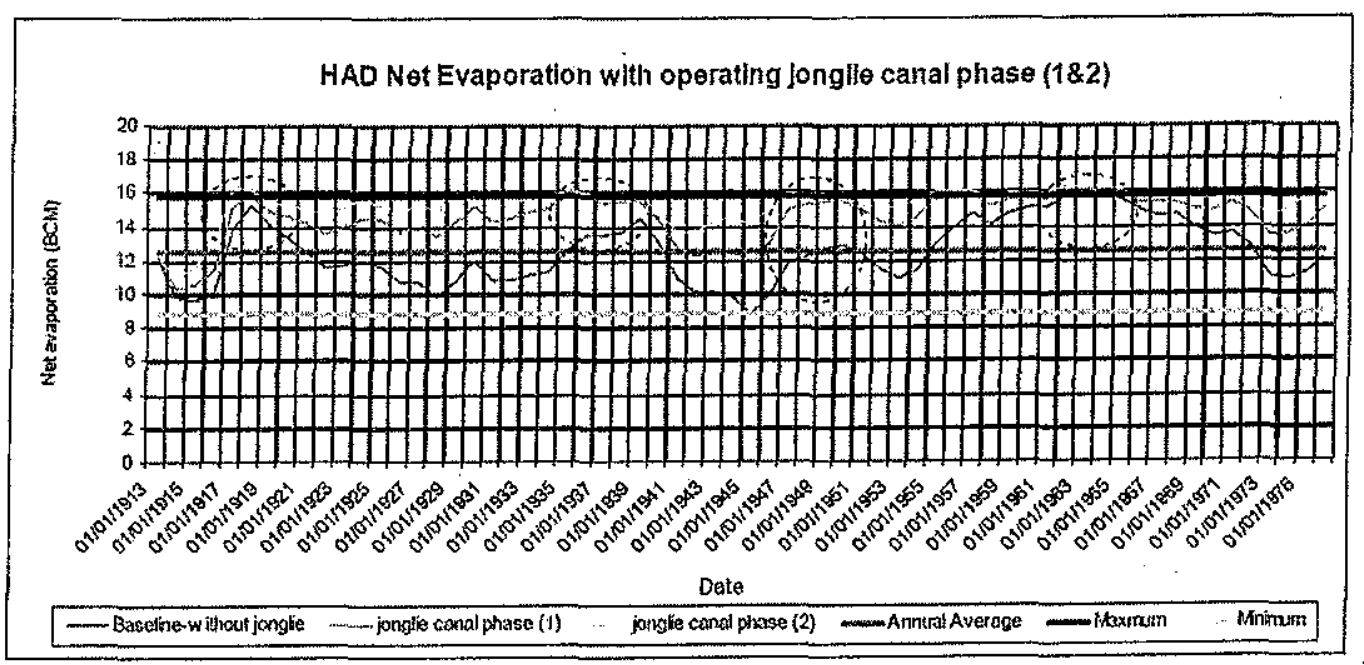

Figure (13) net evaporation at AHD after operating Jonglie Canal Phase 1 and 2 